\title{
COMPARAÇÃO MORFOANATÔMICA DE FOLHAS DE Campomanesia xanthorcapa \\ O. Berg E Campomanesia guaviroba (DC.) Kiaersk. (Myrtaceae) COMO \\ CONTRIBUIÇÃO A FARMACOGNOSIA
}

\author{
COMPARATIVE MORPHOLOGICAL AND ANATOMICAL STUDIES OF LEAVES \\ OF Campomanesia xanthocarpa O. Berg AND Campomanesia guaviroba (DC.) \\ Kiaersk. (Myrtaceae) AS A CONTRIBUTION TO PHARMACOGNOSY
}

\section{Polyanna Cristina Simão SAIBERT'1 ; Mariza Baron ROMAGNOLO²; Adriana Lenita Meyer ALBIERO 3}

1 - Centro de Ciências Biológicas - Programa de Pós-Graduação em Biologia Comparada Universidade Estadual de Maringá. Maringá - Paraná.

2 - Departamento de Biologia - Universidade Estadual de Maringá. Maringá - Paraná.

3 - Departamento de Farmácia - Universidade Estadual de Maringá. Maringá - Paraná.

Autor para correspondência: almalbiero@uem.br

\section{RESUMO:}

Campomanesia Ruiz \& Pav. é um gênero bem delimitado dentro de Myrtaceae, porém o limite entre alguns táxons inferiores é problemático. Desse modo o presente trabalho teve como propósito investigar caracteres morfoanatômicos foliares de Campomanesia xanthocarpa O. Berg e C. guaviroba (DC.) Kiaersk. Contribuindo para a diagnose das espécies. Amostras foram coletadas em um remanescente da Floresta Atlântica no Paraná e submetidas a análises morfológicas, anatômicas, microscopia eletrônica de varredura e testes histoquímicos. Os resultados mostraram grande variação foliar em $C$. xanthocarpa possibilitando a divisão em sete morfotipos, sendo três destes muito próximos a $C$. guaviroba, que apresentou caracteres anatômicos constantes como células epidérmicas com formato isodiamétrico de paredes pouco sinuosas em ambas as faces, cavidades secretoras epidérmicas discretamente inseridas na face abaxial e uma camada de células coletoras entre os parênquimas paliçádico e lacunoso, no mesofilo. A composição histoquímica também se mostrou similar com presença de compostos fenólicos, amido, lipídios e cristais no pecíolo e limbo. Embora $C$. xanthocarpa tenha apresentado grandes variações morfológicas e anatômicas, o padrão anatômico observado em $C$. guaviroba possui características que permitem separá-las.

Palavras chave: Morfologia, anatomia, epiderme, cavidades secretoras, taxonomia, Myrtaceae.

\begin{abstract}
:
Campomanesia Ruiz \& Pav. it is a well-defined genre within Myrtaceae, but the boundaries between their lower taxa are problematic. Thus the present study aimed to investigate leaf morphological and anatomical features of Campomanesia xanthocarpa O. Berg and $C$. guaviroba (DC.) Kiaersk. in an attempt to contribute to the taxonomy of the two species. Well-developed leaves were collected in a remnant of Atlantic Forest and subjected to morphological, anatomical, scanning electron microscopy and histochemical tests. The results showed great variation in leaf $C$. xanthocarpa allowing the division into seven morphotypes, the 5, 6 and 7 very near $C$. guaviroba. Establish boundaries between these
\end{abstract}


species is a complex task, but $C$. guaviroba had constant anatomical characters as epidermal cells with isodiametric format slightly sinuous walls on both sides, epidermal secretory cavities discreetly inserted in abaxial and a layer of collecting cells from the parenchyma palisade and spongy in the mesophyll. Histochemical composition was also similar to the presence of phenolic compounds, starch, lipids and crystalliferous petiole and limbo. Although $C$. xanthocarpa has presented large morphological and anatomical variations, anatomical pattern observed in $C$. guaviroba has subtle features that allow separate them.

Keywords: Morphology, anatomy epiderms, secretory cavities, taxonomy, Myrtaceae.

\section{INTRODUÇÃO}

Diversos autores clássicos fizeram relatos sobre as semelhanças morfológicas entre os táxons de Myrtaceae, essa similaridade dificulta, demasiadamente, a imposição de limites interespecíficos entre alguns grupos. Trabalhos como os de McVaugh (1968), Landrum (1986) e Ladrum \& Kawazaki (1997) que estudaram a morfologia dos gêneros americanos de Myrtaceae foram fundamentais para a caracterização das mirtáceaes brasileiras.

Os representantes de Myrtaceae são marcados pela presença de folhas simples, com cavidades secretoras, flores pentâmeras, presença de cavidade secretora no ápice das anteras, ovário geralmente ínfero, com placentação axial e lóculos bi-pluriovulados, frutos carnosos e secos, floema interno e pontuações ornamentadas nos vasos do xilema (JOHNSON \& BRIGGS, 1984; LANDRUM \& KAWASAKI, 1997; JUDD et al. 2009; SOUZA \& LORENZI, 2012).

Campomanesia apresenta aproximadamente 40 espécies (GOVAERTS et al. 2015), distribuídas exclusivamente pela América tropical e subtropical (LANDRUM 1986, LANDRUM \& KAWASAKI ,1997). Ocorre de norte a sul do Brasil em região de Cerrado e ambientes florestais da Mata Atlântica. São árvores ou arbustos, com folhas de textura e tamanhos variáveis, com tricomas simples e unicelulares em quantidade e localização diversas. Trabalhos anatômicos vêm sendo realizados para a família (CARDOSO \& SAJO, 2006; GOMES et al. 2009) e para Campomanesia (CARNEVALI et al. 2008; OLIVEIRA et al. 2011; ARRUDA et al. 2013; OLIVEIRA, 2013).

Gomes et al. (2009) relaciona alguns caracteres de grande valor taxonômico para separar espécies na família como o formato das células epidérmicas, tricomas dibraquiados ou não, camadas celulares subepidérmicas incolores, além do formato e número das células teto das cavidades secretoras.

Os trabalhos de Oliveira et al. (2011) e Oliveira (2013) contribuíram consideravelmente para o conhecimento morfoanatômico de Campomanesia que possui 
espécies problemáticas como $C$. xanthocarpa com semelhanças consideráveis em relação a C. guaviroba. Os autores relatam a sobreposição entre caracteres morfológicos e anatômicos e também citam outros caracteres como presença e tipo de domácias, tipo de cristalóides da cera epicuticular e configuração do arco vascular no pecíolo para auxiliar a delimitação em Myrtaceae especialmente em Campomanesia.

Campomanesia xanthocarpa é largamente utilizada como planta medicinal e tem usos cientificamente relatados no combate à disenteria, febre, escorbuto, e doenças das vias urinárias (CORREA, 1974; CRAVO, 1994; GEMTCHÚJNICOV, 1976). A infusão de suas folhas apresentou resultados positivos contra o diabetes e auxílio no controle da obesidade em camundongos, conforme estudos de Kataoka e Cardoso (2013), além disso, o extrato das folhas também demonstrou ter ação no controle do colesterol ruim (KLAFKE et al., 2008).

Análises fitoquímicas feitas a partir do extrato das folhas detectaram flavonoides, saponinas, taninos e terpenos, que poderiam justificar as propriedades farmacêuticas relatadas (MARKMAN et al.,2004; KLAFKE et al., 2010). Os flavonóides também estão associados à capacidade antioxidativa descrita para essa planta (ABE et al., 2014).

Campomanesia guaviroba não possui usos medicinais, porém é muito similar a $\mathrm{C}$. xanthocarpa e, portanto, a importância de se realizar estudos descritivos mais completos sobre essa espécie.

O presente trabalho tratará da caracterização morfoanatômica e histoquímica das folhas de C. xanthocarpa e C. guaviroba ocorrentes na Estação Ecológica do Caiuá, importante remanescente de florestal de Mata Atlântica do noroeste Paraná, colaborando com estudos farmacognósticos das espécies.

\section{MATERIAL E MÉTODOS}

\subsection{Coleta e identificação}

O material botânico foi coletado em populações naturais de C. guaviroba (DC.) Kiaersk. Campomanesia xanthocarpa O. Berg ocorrentes em Floresta Estacional Semidecidual na Estação Ecológica do Caiuá, no município de Diamante do Norte - PR. Material testemunho está depositado no Herbário da Universidade Estadual do Paraná (HUEM) - Campus de Maringá sob HUEM 29900 para a primeira espécie, os morfotipos da segunda espécie estão aguardando registro no herbário.

A identificação taxonômica foi feita pela Dr ${ }^{\mathrm{a}}$ Mariza B. Romagnolo, do HUEM, 
Herbário da Universidade Estadual de Maringá e Drạ. Marla Ibrahim Uehbe de Oliveira, da Universidade Tiradentes, em Aracaju - SE. A descrição morfológica seguiu Hickey (1973) e Gonçalves \& Lorenzi (2011).

O material vegetal fresco (folhas) de Campomanesia xanthorcapa e de C. guaviroba foi estudado por meio de fragmentos obtidos das regiões mediana do pecíolo, da base, meio e ápice da nervura central, além do bordo foliar. Os fragmentos foram fixados em FAA 50 e 70\% e conservados em álcool 70\% (JOHANSEN, 1940). Para o preparo de lâminas permanentes as secções foram desidratadas em série etílica crescente, incluídas em historresina Leica ${ }^{\circledR}$ conforme Gerrits (1991) e instruções do fabricante, e posteriormente seccionadas em micrótomo rotativo. As secções foram coradas com azul de toluidina (O’Brien et al. 1964) e montadas entre lâmina e lamínula com Entelan®. Para o preparo de lâminas semi-permanentes as folhas das espécies foram seccionadas a mão livre com auxílio de lâmina de aço, clarificadas com hipoclorito de sódio a 50\%, lavadas em água destilada, neutralizadas em solução com 2 gotas de ácido acético a 7\%, lavadas novamente em água destilada, coradas em solução de azul de astra e safranina (Bukatsch 1972 modificado por Kraus \& Arduin 1997) e montadas entre lâmina e lamínula com glicerina a 50\% (PURVIS et al. 1964). As imagens foram obtidas em câmera fotográfica digital Sony e em microscópio de luz com câmera embutida modelo Leica EZ4D e microscópio Olympus CX31 com câmera acoplada modelo Moticam 2300. A análise e registro das imagens foram realizados com auxílio de software. As escalas referentes às ilustrações foram obtidas utilizando lâmina micrométrica nas mesmas condições ópticas para cada caso. As pranchas foram elaboradas utilizando CoreIDRAW Graphics Suite X5.

A superfície das amostras da região mediana das folhas das duas espécies foram analisadas ao microscópio eletrônico de varredura Shimadzu SS-550 Superscan do Complexo de Centrais de Apoio a Pesquisa (COMCAP) da Universidade Estadual de Maringá - UEM.

Os testes histoquímicos foram realizados em material vegetal fresco e fixado, conforme as recomendações propostas por Ascensão (2003), em secções obtidas a mão livre, tratadas com Sudan, III, IV e Black para revelação de lipídeos em geral (JENSEN, 1962); solução de cloreto férrico a 10\% para compostos fenólicos (JOHANSEN, 1940); vermelho de rutênio a 0,02\% para compostos mucilaginosos (JOHANSEN, 1940); solução de Lugol, para amido (JENSEN, 1962); ácido sulfúrico (5\% e 10\%) para identificação de cristais de oxalato de cálcio (JENSEN, 1962). 


\section{RESULTADOS}

\subsection{Morfologia}

As folhas de Campomanesia xanthocarpa medem de 6,0-10,0 cm de comprimento por 2,5-5,0cm. O formato variou de oval a elíptico-lanceolado, com base de obtusa a aguda, ápice de agudo a acuminado. As margens vão de onduladas a lisas, com textura membranácea a levemente cartácea (Fig. 1A). O padrão de venação é camptódromobronquidódromo, a cor varia de verde claro a verde escuro e com indumento pubescente, com filotaxia oposta cruzada.

Em C. xanthocarpa, grande plasticidade fenotípica foi observada, possibilitando a identificação de 7 morfotipos diferentes $(X 1-X 7)$ descritos com base na forma do limbo, base, ápice e bordo, além da textura e coloração (Fig. 1B), dos quais, três são muito semelhantes a $C$. guaviroba (Fig. $1 \mathrm{~F}$ ) e cujos dados estão comparados na tabela 1.

Em C. guaviroba a folha é simples de coloração verde claro a escuro, filotaxia oposta, medindo entre 6,5-12 cm de comprimento por 3,5-5,5cm de largura, com formato de oblongo a elíptico, de margem lisa a levemente ondulada e textura membranácea, com indumento pubescente (Fig. 1E - 1F). As domácias, em formato de bolsa, ocorrem na junção da nervura central com as secundárias, assim como em $C$. xanthocarpa, tricomas tectores foram observados distribuídos por todo o limbo, com incidência maior na face abaxial e sobre as nervuras (Fig. 1C-1D).

$\mathrm{Na}$ espécie estudada, bem como nos morfotipos observados, a margem é levemente revoluta, em especial no terço superior da lamina foliar, destacando-se a presença de cavidades secretoras (Fig. 1G). A nervura principal e as secundárias mostramse impressas na face adaxial e proeminentes na face abaxial e seguem o padrão de venação do tipo camptódromo-bronquidódromo (Fig. 1F).

As cavidades secretoras são visíveis a olho nu e estão presentes no limbo e pecíolo dos morfotipos de C. xanthocarpa e em C. guaviroba. No material fresco, mostram-se como pontuações amarelo-alaranjadas (Fig.1H).

O pecíolo, em ambas espécies, manteve o padrão côncavo-convexo ou planoconvexo, medindo entre $0,5-1,5 \mathrm{~cm}$ de comprimento, de cor verde ou vinácea, alongado e fino com tricomas tectores curtos, não sendo um caráter significativo para a distinção.

Nos morfotipos de $C$. xanthocarpa a superfície da lâmina foliar em suas faces possui características variáveis, o que não ocorre em C. guaviroba (Tab. 2). 
Em vista frontal a superfície do limbo nos morfotipos de $C$. xanthocarpa mostra cutícula lisa em ambas as faces (Fig. 2A). Os tricomas tectores são unicelulares, unisseriados, variam de curtos a longos ocorrendo com maior ou menor frequência, sendo que na base destes as células da epiderme estão em disposição radial (Fig. 2B - 2D). As células epidérmicas, em suas faces abaxial e adaxial, possuem diferentes formatos e mostram-se isodiamétricas ou retangulares em alguns morfotipos e, de paredes com contorno sinuoso, principalmente, as anticlinais, em outros (Fig. 2E - 2F).

As cavidades secretoras epidérmicas, em geral, apresentam um par de células, denominadas células-teto e a parede de contato dessas células tem um contorno que varia do liso ao fortemente sinuoso, o que permite denominá-las de reniformes (Fig. 2G - 2H).

A disposição das células epidérmicas ao redor das células-teto pode ter arranjo radial evidente ou discreto (Fig. $2 \mathrm{G}$ - 2H). Estas variações são mais visíveis quando comparadas as faces abaxial e adaxial. Apesar da cutícula lisa, foi possível observar a deposição de cera (Fig. 2B e 2G) nos estômatos.

Anatomia

A folha é hipoestomática e os complexos estomáticos são predominantemente do tipo anomocítico e paracítico em todos os morfotipos e em C. guaviroba (Fig. 3A - 3B).

O pecíolo dos morfotipos, em secção transversal, na região mediana é planoconvexo e está constituído por epiderme uniestratificada, cuticularizada. Os tricomas tectores são unicelulares e unisseriados e estão distribuídos as duas faces, com exceção de $\mathrm{X} 7$, onde não ocorrem (Fig. 3C). A região cortical está constituída por um a dois estratos de células colenquimatosas e de 6 a 12 de células parenquimáticas isodiamétricas com idioblastos de conteúdo fenólico e cristalífero contendo drusas e cristais prismáticos de oxalato de cálcio (Fig. 3C detalhe), com variações entre os morfotipos, destacando-se as drusas no morfotipo X3.

O sistema vascular está constituído por um único feixe vascular anfiflóico em forma de arco com abertura voltada para face adaxial. A abertura do arco vascular mostrou variação nos morfotipos estudados podendo apresentar-se mais involuta em X7, por exemplo, em comparação com os demais.

Ao redor do feixe, grupos de fibras esclerenquimáticas, formando uma bainha de descontínua a contínua, com exceção em de X3, que não apresentou fibras. O xilema ocupa a região central e os elementos traqueais estão intercalados com raios parenquimáticos em X2 e X3. Cavidades secretoras na epiderme e subepidérmicas foram observadas (Fig. 3C).

A nervura central, em secção transversal, mostra constituição semelhante da base 
(Fig. 3D) até o ápice (Fig. 3E) nos morfotipos. A epiderme é uniestratificada, cuticularizada com tricomas tectores, unicelulares e cavidades secretoras epidérmicas. A região cortical pode apresentar colênquima subepidérmico, idioblastos contendo drusas e cristais prismáticos de oxalato de cálcio, assim como idioblastos fenólicos e com grãos de amido, além de cavidades secretoras subepidérmicas (Fig. 3D).

O sistema vascular está constituído por um único feixe vascular anfiflóico, com bainha esclerenquimática contínua ou descontínua, da base até a região mediana da folha. No ápice o feixe vascular é colateral (Fig. 3E).

O limbo, em secção transversal, apresenta mesofilo dorsiventral, epiderme uniestratificada em ambas as faces, o parênquima paliçádico está constituído por uma camada de células e o lacunoso apresenta de $3-7$ estratos de células (Fig. 3F), com espaços intercelulares e câmaras subestomáticas.

No bordo foliar que mostra-se ligeiramente fletido e as células da epiderme são menores quando comparadas com as do limbo e o mesofilo está constituído de células parenquimáticas de paredes mais espessadas e formato arredondado, com espaços intercelulares reduzidos, podendo ou não apresentar cavidades secretoras (Fig. 3G).

Em C. guaviroba a folha é hipoestomática, a epiderme é cuticularizada (Fig. 4A4B) com tricomas tectores unicelulares e unisseriados, que ocorrem nas duas faces e apresentam tamanhos diferentes, distribuindo-se pelo limbo e sobre as nervuras. As células da epiderme na face abaxial são quadrangulares de contorno sinuoso, dispostas de forma radial ao redor das células-teto das cavidades secretoras que, mostram-se abaixo do nível das demais células da epiderme (Fig. 4A - 4D). Na face adaxial são isodiamétricas (Fig. 4B), e as células teto das cavidades secretoras são muito semelhantes as da epiderme (fig. 4C). Os são estômatos, predominantemente anomocíticos e paracíticos (Fig. 4E).

O pecíolo em secção transversal é circular, com epiderme cuticularizada, uniestratificada. A região cortical está constituída por 15 a 17 estratos de células isodiamétricas. O sistema vascular está constituído por um único feixe, bicolateral, em arco, muito semelhante a base da folha, com exceção dos grupos de fibras esclerenquimáticas (Fig. 4F - 4G).

Em secção transversal, o mesofilo é dorsiventral com uma camada de parênquima paliçádico e 3-5 de lacunoso, região em que foram observadas células coletoras (Fig. 4H). Os feixes vasculares de menor calibre estão envoltos por bainha esclerenquimática que com frequência estendem-se de uma face à outra. As cavidades secretoras e os idioblastos contendo cristais prismáticos, quando ocorrem, podem atingir a extensão tranversa dos 
parenquimas (Fig. 4H). O bordo foliar mostra feixes vasculares colaterais secundários e cavidades secretoras (Fig. 4I).

Os testes histoquímicos realizados com Sudan III, IV e Black B revelaram a cutícula da lâmina foliar e do pecíolo, além do conteúdo das cavidades secretoras nestas mesmas regiões (Fig. 5A-5B). O teste com cloreto férrico $10 \%$ revelou conteúdo fenólico em idioblastos no córtex do pecíolo, nervura central e mesofilo. O lugol evidenciou grãos de amido, em quantidades variáveis, ao redor do feixe vascular no mesofilo, pecíolo e em menor quantidade na nervura central (Fig. 5C).

Da mesma maneira que foram averiguadas variações morfológicas entre os morfotipos de C. xanthocarpa, na análise anatômica algumas variações também foram observadas como tamanho dos tricomas na folha, a variação no formato e tamanho das células epidérmicas, contorno das células teto das cavidades secretoras e arranjo das células epidérmicas ao redor destas cavidades, além da quantidade de fibras esclerenquimáticas ao redor do feixe vascular.

\section{DISCUSSÃO}

Semelhanças morfológicas interespecíficas não é novidade dentro de Myrteae sendo relatadas desde os trabalhos de McVaugh (1968), na tentativa de levantar caracteres de diferenciação entre espécies deste grupo para alocá-las conforme sua real linha evolutiva, pesquisas voltadas a taxonomia e sistemática vêm sendo amplamente executados nos últimos anos (CARDOSO \& SAJO, 2006; Costa \& DORNELAS, 2008; ROCHA et al. 2008, CARDOSO et al. 2009; GOMES et al. 2009; SANTOS et al. 2014; LIMA et al. 2015; SANTOS et al. 2015; SILVA \& MAZINE 2016).

Dentro de Myrteae, Campomanesia mostra-se um grupo monofilético (Costa 2009), porém apresenta grandes conflitos taxonômicos e filogenéticos intraespecíficos, e vem sendo investigado quanto sua morfologia, anatomia e composição genética. Assim, duas coisas importantes têm sido observadas nesses estudos, a primeira é que ocorre sobreposição de algumas características morfológicas, anatômicas e até genéticas entre as espécies, como mostra os trabalhos de Costa \& Forni-Martins (2006), Carnevalli et al. (2008), Santos \& Marchiori (2009) e Oliveira et al. (2011), e a segunda é que variações intraespecíficas são muito comuns, muitas vezes ocorrendo em caracteres utilizados como determinantes para diagnose de espécies, como por exemplo a natureza das células ao redor do feixe vascular, a forma e disposição do feixe vascular no pecíolo, o formato e 
padrão foliar de venação entre capilares Costa et al. (1995) e Cardoso \& Sajo (2004).

Uma ideia que vem se confirmando é que espécies deste grupo podem sofrer influência significativa do ambiente, tendo caracteres distintos conforme o habitat que ocupa, C. guazumifolia é um exemplo, no trabalho de Lima et al. (2011), em Mata Atlântica no Paraná, apresenta pecíolo e nervuras densamente cobertos por tricomas de modo que a folha é discolor, já os representantes encontrados por Oliveira et al. (2012) na flora da Bahia em região de cerrado apresentam folhas lisas e glabras, essa divergência de dados tem dificultado o estabelecimento de um padrão morfoanatômicos para algumas espécies, e pode gerar sobreposição na descrição taxonômica.

As variações foliares entre indivíduos de $C$. xanthocarpa foram relatadas em alguns trabalhos realizados em Mata Atlântica (Floresta Ombrófila Mista), como Wesp (2014) que analisou caracteres morfológicos gerais e relatou predominância de folhas glabras, diferente do que foi constatado neste trabalho.

Krupek \& Lima (2012) descreveram variações estruturais em folhas desta espécie sobre diferentes condições de luminosidade, e destacou que plantas presentes em ambientes sombreados, como sub-bosques, tendem a apresentar folhas maiores, com estômatos em maior quantidade e lâmina foliar bem desenvolvida.

A variação foliar observada que permitiu concluir que o morfotipo X1 é o mais distante de $C$. guaviroba e o morfotipo X6 é o mais se assemelhante a $C$. guaviroba, pois possui folhas maiores e mais largas, de formato oval a oblongo com ápice bem acuminado e textura levemente cartácea, porém em campo, os brotos foliares e folhas jovens, tem tons avermelhados.

O padrão de venação observado entre as espécies estudadas foi do tipo camptódromo-bronquidódromo, como relatado por Carrara (1997), Cardoso \& Sajo (2006) e Oliveira et al (2011) em seus estudos sobre a nervação foliar em mirtáceas brasileiras, e por e em folhas de Campomanesia, embora Klucking (1988) tenha considerado o padrão acródromo mais recorrente em Myrtaceae.

A presença de domácias pode ser um caráter interessante para a identificação de espécies em Myrtaceae, pois foram encontrados somente em Legrandia e Campomanesia (LANDRUM, 1986; 2001).

Cerrado e Lima et al. (2011) observaram domácias em, C. guaviroba, C. xanthocarpa, $C$. reitziana e $C$. neriiflora e destacam a variação morfológica encontrada em C. guaviroba e C. xanthocarpa, em levantamento florístico para o gênero, no Paraná

Algumas características anatômicas são recorrentes em Myrtaceae, tais como a 
presença de cavidades secretoras no mesofilo, ocorrência de floema interno ao xilema, idioblastos com conteúdo fenólico ou cristais de oxalato de cálcio agrupados ou solitários (SOLEREDER 1908; METCALFE \& CHALK 1950), desta maneira, tais características não deram suporte para a separação entre as espécies estudadas

O formato das células epidérmicas de C. xanthocarpa condiz com os resultados obtidos por Oliveira (2013) para a mesma espécie, variando entre leve a fortemente sinuoso, bem como os tricomas, que seguem o padrão geral para a família, pois segundo Metcalfe \& Chalk (1979) os tricomas costumam ser unicelulares e não ramificados em Myrtaceae.

Com relação aos estômatos, Arruda \& Fontenelle (1994) afirmaram que não há um padrão característico para a família, todavia, estudos recentes demonstram a predominância de estômatos anomocíticos em Campomanesia phaea (Adati 2001), C. adamantium, C. cavalcantina, C. eugenioides var. eugenioides e var. desertorum, C. rhombea e C. xanthocarpa var. xanthocarpa e var. litorallis (Oliveira 2013), e Pimenta pseudocaryophyllus (CUSTÓDIO, et al. 2013), como visto também para as espécies descritas neste trabalho.

As cavidades secretoras em C. guaviroba, apresentaram um par de células teto com paredes anticlinais contíguas sinuosas, também observado para Eugenia uniflora (NEVES \& DONATO, 1989), Pisidium widgrenianum, sinônimo de $P$. rufum (DONATO \& MORRETES, 2005) e Pimenta pseudocaryophyllus (PAULA et al. 2008).

Para os morfotipos de $C$. xanthocarpa o número de células teto não variou, porém o contorno das paredes anticlinais contíguas apresentou contorno sinuoso e reto, além disso, o disco formado por células epidérmicas ao redor das cavidades mostrou-se mais evidente nos morfotipos X1, X2, X3, X4, X5 e menos evidente na face adaxial dos morfotipos X6 e X7. Desta maneira, os padrões observados nesta pesquisa estão dentro do gradiente observado para a família.

Variações deste padrão foram encontradas por alguns autores, Donato \& Morretes (2009; 2011) que relatam uma única célula-teto com formato entre poligonal, elíptica ou arredondada para Eugenia brasiliensis e Myrcia multiflora. Gomes et al. (2009) encontrou três células-teto em Campomanesia adamantium, e quatro para Myrcia decrescen.

O mesofilo segue o padrão dorsiventral e se apresenta muito similar entre $C$. xanthocarpa e C. guaviroba, porém na segunda espécie é possível observar uma camada de células coletoras, entre os parênquimas paliçádico e lacunoso, esse caráter foi relatado para outras mirtáceas como Eugenia umbeliflora (Medeiros 2000), Psidium widgrenianum 
(DONATO \& MORRETES, 2005), Eugenia brasiliensis (DONATO \& MORRETES, 2007), Eugenia florida (DONATO \& MORRETES, 2009), Myrcia multiflora (DONATO \& MORRETES, 2011), todavia sua origem e função não foram relatadas.

A histoquímica do mesofilo demonstrou similaridade com o que ocorre em Myrtaceae, apresentando grande quantidade de taninos (SOLEREDER 1908; METCALFE \& CHALK 1950; CRONQUIST 1981; APPEZZATO-DA-GLÓRIA \& CARMELLOGUERREIRO 2006), idioblastos contendo cristais prismáticos de oxalato de cálcio e amido. Os lipídios foram evidenciados somente nas cavidades secretoras e na cutícula, e assim como o pecíolo obteve resultado semelhante a $C$. xanthocarpa e em $C$. guaviroba.

\section{CONCLUSÃO}

C. xanthocarpa apresentou gradiente de variação morfológico e anatômico muito grande neste trabalho, sendo dividida em sete morfotipos, a partir do quinto confundem-se com C. guaviroba, porém essa última espécie demonstrou um padrão na anatomia da epiderme, principalmente na face adaxial, onde as células epidérmicas mostram paredes pouco sinuosas, de formato isodiamétrico, cavidades secretoras epidérmicas discretamente inseridas entre as demais células epidérmicas, não formando um disco característico observado nos morfotipos X1, X2, X3, X4 e X5.

Foi observada, somente para essa espécie, a presença de uma camada de células coletoras entre os parênquimas paliçádico e lacunoso no mesofilo. Os morfotipos X6 e X7 de $C$. xanthocarpa são muito semelhantes na morfologia e anatomia com C. guaviroba, e podem gerar confusão na identificação entre elas em fase não reprodutiva, por isso, analisar de forma cautelosa a anatomia do mesofilo, para identificar essa camada de células coletoras é indispensável, o que confere valor taxonômico a essas estruturas.

\section{AGRADECIMENTOS}

A Drª Marla I. U. de Oliveira pelo auxílio na identificação, ao Complexo de Centrais de Apoio a Pesquisa (COMCAP) da Universidade estadual de Maringá - UEM nas análises de Microscopia Eletrônica de Varredura e a Coordenação de Aperfeiçoamento de Pessoal de Nível Superior (CAPES) pela concessão da bolsa de estudos. 


\section{REFERÊNCIAS}

APPEZZATO-DA-GLÓRIA, B.; CARMELLO-GUERREIRO, S.M. Ed. UFV, 2006.

ARRUDA, R. C. O.; FONTENELLE, G. B. Contribuição ao estudo da anatomia foliar de Psidium cattleyanum Sabine (Myrtaceae). Revista Brasileira de Botânica, v. 17, p. 25-35, 1994.

ARRUDA, M. F. C.; MIGUEL, O. G.; STUELP-CAMPELO, P. M.; DUARTE, M. R. Leaf and stem morpho-anatomy of Campomanesia guazumifolia (Cambess.) O. Berg, Myrtaceae. Latin American Journal of Pharmacy, v. 32, n. 9, p.1342-8, 2013.

ASCENSÃO L. Técnicas histoquímicas convencionais de microscopia de fluorescência aplicadas em espécies de Cerrado. UNESP. 2003.

BARROSO, G. M.; AMORIM M. P., PEIXOTO, A. L., ICHASO, C. L. F. Frutos e sementes: morfologia aplicada à sistemática de dicotiledôneas. Viçosa, UFV Impr. Univ. 2004.

BERG, O. Revisio Myrtacearum Americae. Linnaea, v. 27, p. 1 -472, 1855-56.

BERG, O. Myrtaceae. In: Von Martius CFP (eds.). Flora Brasiliensis, v.14, p. 1-655, 1857-59.

ZAPPI, D. Growing knowledge: an overview of Seed Plant diversity in Brazil. Rodriguésia, v. 66, n.4, p.1085-1113, 2015.

BUKATSCH, F. Bemerkungen zur doppelfärbung astrablau-safranin. Mikrokosmos. v. 61, n. 8, p.255, 1972.

CARDOSO, C. M. V.; SAJO, M. G. Vascularização foliar e a identificação de espécies de Eugenia L. (Myrtaceae) da bacia hidrográfica do Rio Tibagi, PR. Revista Brasileira de Botânica, v.27, n.1, p. 47-54, 2004.

CARDOSO, C. M. V.; SAJO, M. G. Nervação foliar em espécies brasileiras de Myrtaceae Adams. Acta Botanica Brasilica, v. 20, n.3, p. 657-669, 2006. 
CARDOSO, C.M.V., PROENÇA SL, SAJO MG. Foliar anatomy of the subfamily Myrtoideae (Myrtaceae). Australian Journal of Botany, v.57, p.148-161, 2009.

CARNEVALI, T. O., CRESPAN, P. A., VIEIRA, M. C., RAMOS, D. D., SOUSA, N. H., SILVA, P.E.M. Estudo anatômico comparativo da guavira (Campomanesia adamantium Camb.), Horticultura Brasileira, v. 26, n. S905-S910, 2008.

CARRARA, M. R. Estudo das espécies de Campomanesia Ruiz \& Pav. (Myrtaceae, Myrtinae) ocorrentes no estado do Rio de Janeiro. Dissertação de Mestrado. Universidade Federal do Rio de Janeiro, Brasil. 1997.

COSTA, C. G.; MACHADO, R. D.; FONTENELLE, J. B. Sistema vascular em folhas de Eugenia L.(Myrtaceae). Bradea, v. 6, n. 42, p.345-356, 1995.

COSTA, I. R.; FORNI-MARTINS, E.R. Chromosome studies in Brazilian species of Campomanesia Ruiz \& Pávon and Psidium L. (Juss.). Caryologia v. 59, n.1, p. 7-13, 2006.

COSTA, I. R.; DORNELAS, M.C. Nuclear genome size variation in fleshy-fruited Neotropical Myrtaceae, Plant Systematics and Evolution, v. 276, p. 209-217, 2008.

COSTA, I.R. Estudos evolutivos em Myrtaceae: aspectos citotaxonômicos e filogenéticos em Myrteae, enfatizando Psidium e gêneros relacionados. Tese de Doutorado. Universidade Estadual de Campinas. Campinas - SP, Brasil, 2009.

CUSTÓDIO, D. L.; KOLB, R. M.; FARIA, T. J.; BIANCHINI E. Pimenta pseudocaryophyllus (Gomes) L.R. Landrum (Myrtaceae): stem and leaf anatomy of a medicinal plant. Semina Ciências Biológicas e da Saúde, v. 34, n. 2, p. 111-124, 2013.

DONATO, A. M.; MORRETES, B. L. Estudo anatômico das folhas de Psidium widgrenianum Berg. (Myrtaceae), uma potencial espécie medicinal. Revista Brasileira de Farmácia, v. 86, n.2, p. $65-70,2005$.

DONATO, A. M.; MORRETES, B. L. Anatomia foliar de Eugenia brasiliensis Lam. (Myrtaceae) proveniente de áreas de restinga e de floresta. Revista Brasileira de 
Farmacognosia, v. 17, n. 3, p. 426 - 443, 2007.

DONATO, A. M.; MORRETES, B. L. Anatomia foliar de Eugenia florida DC. (Myrtaceae). Revista Brasileira de Farmacognosia, v.19, n. 3, p. 7759-770, 2009.

DONATO, A. M.; MORRETES, B. L. Morfo-anatomia foliar de Myrcia multiflora (Lam.) DC. - Myrtaceae. Revista Brasileira de Plantas Medicinais, v. 10, n. 1, p.43-51, 2011.

FORZZA, R.C.; BAUMGRATZ, J. F. A.; BICUDO, C. E. M. Catálogo de plantas e fungos do Brasil. Rio de Janeiro, Andrea Jakobson Estúdio. 2010.

FRANKLIN, G.L. Preparation of thin sections of synthetic resins and wood-resin composites, ad a new macerating method for wood. Nature, n. 155, p.51, 1945.

GOMES, D. M. S; NEVES, L. J. Anatomia foliar de Gomidesia spectabilis (DC) Berg. e Gomidesia nitida (Vell.) Legr. (Myrtaceae). Rodriguésia, v. 45/49, v. 71/75, p.51-70. 1997.

GOMES, S. M.; SOMAVILLA, N. S. D. N.; GOMES-BEZERRA, K. M.; MIRANDA, S. C.; CARVALHO, O.S.; GRACIANO-RIBEIRO, D. Anatomia foliar de espécies de Myrtaceae: contribuições à taxonomia e filogenia. Acta Botanica Brasilica, v. 23, n.1, p. 223-238. 2009.

GONÇALVES, E.G., LORENZI, H. Morfologia Vegetal: organografia e dicionário ilustrado de morfologia das plantas vasculares. 2ed. São Paulo: Instituto Plantarum de Estudos de Flora. 2011.

GOVAERTS, R.; SOBRAL, M.; ASHTON, P. World Checklist of Myrtaceae. Royal Botanic Gardens, Kew. 2015. Disponível em <http://www.kew.org/wcsp/>. Acesso em: 27 de maio de 2016.

HADDAD, A.; SESSO, A.; FARINA, M. Técnicas básicas de microscopia eletrônica aplicadas às ciências biológicas. Eds. Wanderley de Souza. Rio de Janeiro, Sociedade Brasileira de Microscopia, 1998.

HICKEY, L. J. Classification of the Architecture of Dicotyledonous Leaves. American Journal of Botany, v. 60, n. 1, p. 17-33, 1973. 
JENSEN, W. A. Botanical histochemistry: Principle and practice. San Francisco: W. H. Freeman. 1962.

JOHANSEN, D. A. Plant microtechnique. New York: McGraw-Hill. 1940.

JONHSON, L. A. S.; BRIGGS, B. G. Myrtales and Myrtaceae - a phylogenetic analysis. Annals of the Missouri Botanical Garden, v. 71, n.3, p.700-756, 1984.

JUDD, W. S.; CAMPBELL, C.S.; STEVENS, P.F.; KELLOGG, E. A.; DONOGHUE, M. J. Sistemática Vegetal: Um Enfoque filogenético. 3ed. Porto Alegre, Artmed. 2009.

KLUCKING, E.P. Leaf venation patterns - Myrtaceae. Berlin, J. Cramer. 1988.

KRAUS, J. E.; ARDUIN, M. Manual básico de métodos em morfologia vegetal. Rio de Janeiro, EDUR. 1997.

KRUPEK, R. A.; LIMA, A.G. Variação na estrutura foliar de guabiroba (Campomanesia xanthocarpa Berg.) sob diferentes condições de luminosidade em um remanescente de Floresta Ombrófila Mista. Ambiência. Revista do Setor de Ciências Agrárias e Ambientais. v. 8, n. 2, p. 293-305, 2012.

LANDRUM, L. R. Campomanesia, Pimenta, Blepharocalyx, Legrandia, Acca, Myrrhinium and Luma (Myrtaceae). Flora Neotropica, v. 45, p. 7-72, 1986.

LANDRUM, L. R. Two new species of Campomanesia (Myrtaceae) from Espírito Santo and Bahia, Brazil. Brittonia, v. 53, n. 4, p. 534-538, 2001.

LANDRUM, L. R.; KAWASAKI, M. L. The genera of Myrtaceae in Brazil: an illustrated synoptic treatment and identification keys. Brittonia, v. 49, n. 4, p. 508-536, 1997.

LEGRAND, C. D.; KLEIN, R. M. Mirtáceas - Campomanesia, Feijoa, Britoa, Myrrhinium, Hexaclamys, Siphoneugena, Myrcianthes, Neomitranthes e Psidium. In: Reitz, R. (Ed.). Flora ilustrada catarinense. Itajaí, CNPq/IBDF/HBR. p. 573-634, 1977. 
LIMA, D. F.; GOLDENBERG, R.; SOBRAL, M. O gênero Campomanesia (Myrtaceae) no estado do Paraná, Brasil. Rodriguésia, v. 62, n. 3, p. 683-693, 2011.

LIMA, D.F.; CADDAH, M. K.; GOLDENBERG, R. A família Myrtaceae na llha do Mel, Paranaguá, Estado do Paraná, Brasil. Hoehnea, v. 42, n. 3, p. 497-519, 2015.

LORENZI, H.; LACERDA, M. C. T.; BACHER, L. B. Frutas no Brasil nativas e exóticas (de consumo in natura). São Paulo, Instituto Plantarum de estudos da flora. 2015.

MATOS, C. H. C.; PALLINI, A.; PINTO, C. M. F.; VENZON, M.; REZENDE, D. D. M.; FREITAS, R. C. P. Caracterização morfológica e classificação da superfície foliar de pimentas quanto à presença de tricomas e domácias. Horticultura Brasileira, v. 29, p. 181-186, 2011.

MEDEIROS, J.D. Anatomia foliar de Eugenia Umbelliflora (Berg.) Myrtaceae. Biotemas, v. 13, n. 1, p. 7-20, 2000.

MCVAUGH, R. The genera of American Myrtaceae. Taxon, v. 17, n. 4, p. 354-418. 1968.

METCALFE, C. R.; CHALK, L. Anatomy of the dicotyledons: Leaves, stem, and wood in relation to taxonomy with notes on economic uses. Oxford, Clarendon Press. 1950.

METCALFE, C. R,; CHALK, L. Anatomy of the dicotyledons. Oxford, Clarendon Press. 1979.

MORAES, T. M. S.; RABELO, G. R.; ALEXANDRINO, C. R.; SILVA-NETO, S. J.; CUNHA, M. Anatomia e micromorfologia comparada da folha de espécies de Psychotria (Rubiaceae) da Floresta Atlântica. Acta Botanica Brasilica, v. 25, n. 1, p. 178-190, 2011.

NEVES LJ, DONATO AM. Contribuição ao estudo de Eugenia uniflora L. (Myrtaceae). Bradea 5: 275-284, 1989.

O'BRIEN, T. P.; FEDER, N.; MCCULLY, M. E. Polychromatic staining of plant cell walls by toluidine blue. Protoplasma, v. 59, n. 2, p. 368-373, 1964.

OLIVEIRA, M. I. U.; FUNCH, L. S.; SANTOS, F. A. R.; LANDRUM, L. R. Aplicação de 
caracteres morfoanatômicos foliares na taxonomia de Campomanesia Ruiz \& Pavón (Myrtaceae). Acta Botanica Brasilica, v. 25, n. 2, p. 455-465, 2011.

OLIVEIRA, M. I. U.; FUNCH, L. S.; LANDRUM, L. R. Flora da Bahia: Campomanesia (Myrtaceae). Sitientibus série Ciências Biológicas, v. 12, n. 1, p. 91-107, 2012.

OLIVEIRA, M. I. U. Estudos taxonômicos e populacionais em Campomanesia Ruiz \& Pavón (Myrtaceae, Myrteae), com ênfase no "Complexo Campomanesia xanthocarpa". Tese de Doutorado. Universidade Estadual de Feira de Santana, 2013.

PAULA, J. A. M.; PAULA, J. R.; BARA, M. T. F.; REZENDE, M. H.; FERREIRA, H. D. Pharmacognostic study about Pimenta pseudocaryophyllus (Gomes) L. R. Landrum leaves - Myrtaceae. Revista Brasileira de Farmacognosia, v. 18, n. 2, p. 265-278, 2008.

PURVIS, M. J.; COLLIER, D. C.; WALLS, D. Laboratory techniques in botany. London, Betterwonths. 1964.

ROBARDS, A. W. An introduction to techniques for scanning electron microscopy of plant cells. In: Hall JL, Hawes C. (orgs.) Electron microscopy and cytochemistry of plant cells. New York, Elsevier. 1978.

ROCHA, L.D.; PREUSSLER, K. H.; PEGORINI, F.; FARIAS, V.; MARANHO, L.T. Estudo anatômico comparativo da casca do caule do araçá-amarelo e araçá-vermelho, Psidium cattleianum Sabine, Myrtaceae. Acta Botanica Brasilica, v. 22, n. 4, p. 1114-1122, 2008.

SANTOS, S. R.; MARCHIORI, J. N. C. Caracterização microscópica do lenho de Campomanesia xanthocarpa O. Berg (Myrtaceae). Balduinia, v. 18, p. 10-14, 2009.

SANTOS, S. R.; MARCHIORI, J. N. C.; SIEGLOCH, A. M. Diversidade estrutural em Eugenia L. (Myrtaceae). Ciência Florestal, v. 24, n. 3, p. 785-792, 2014.

SANTOS, S. R.; SIEGLOCH, A. M.; MARCHIORI, J. N. C. Análise de agrupamento de 16 gêneros e 71 espécies de Myrteae, com base em dados da anatomia da madeira. Balduinia, v. 47, p. 24-33, 2015. 
SILVA, A.T.; MAZINE, F. F. A família Myrtaceae na Floresta Nacional de Ipanema, Iperó, São Paulo, Brasil. Rodriguésia, v. 67, n. 1, p. 203-223, 2016.

SOLEREDER, H. Sistematic anatomy of the dicotyledons. Oxford, Clarendon Press. 1908.

SOUZA, R. S. O. C.; MARQUETE, O. Miconia tristis Spring e Miconia doriana Cogn. (Melastomataceae): anatomia do eixo vegetativo e folhas. Rodriguésia, v. 51, n. 78/79, p. $133-142,2000$.

SOUZA, V. C.; LORENZI, H. Botânica Sistemática: Guia ilustrado para identificação das famílias de Fanerógamas nativas e exóticas no Brasil, baseado em APG III. 3ed. Nova Odessa, Instituto Plantarum. 2012.

WESP, C. L. Caracterização morfológica e físico-química de guabirobeiras (Campomanesia spp.) acessadas no estado do Rio Grande do Sul, Brasil. Tese de Doutorado. Universidade Federal do Rio Grande do Sul, Brasil. 2014.

WILSON, P. G.; O'BRIEN, M. M.; GADEK, P. A.; QUINN, C. J. Myrtaceae revisited: a reassessment of infrafamiliar groups. American Journal of Botany, v. 88, n. 11, p. 2013 2025, 2001.

WILSON, P. G.; O'BRIEN, M. M.; HESLEWOOD, M. M.; QUINN, C. J. Relationships within Myrtaceae sensu lato based on a matK phylogeny. Plant Systematics and Evolution, v. 251, p. 3-19, 2005. 
ANEXO

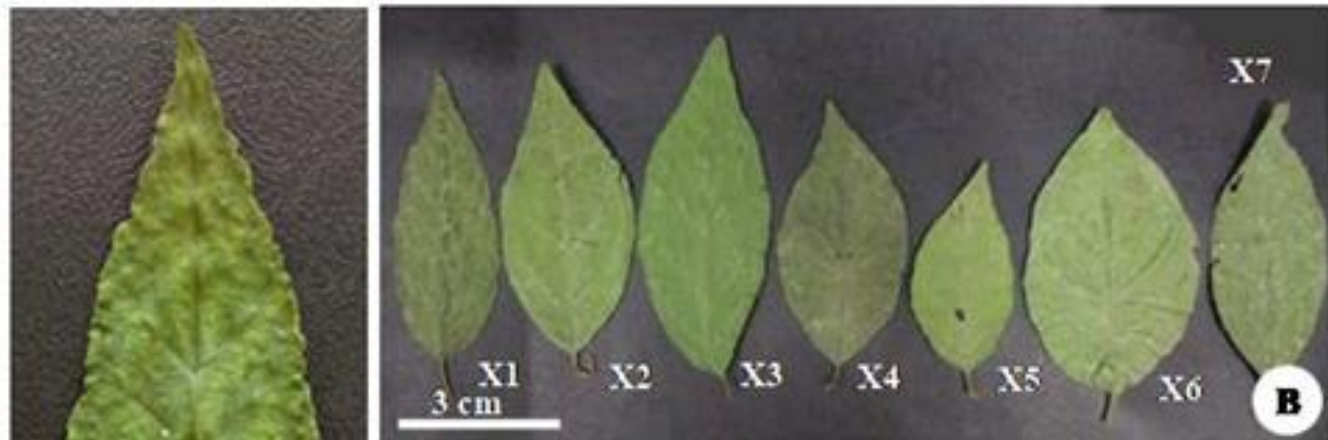

B
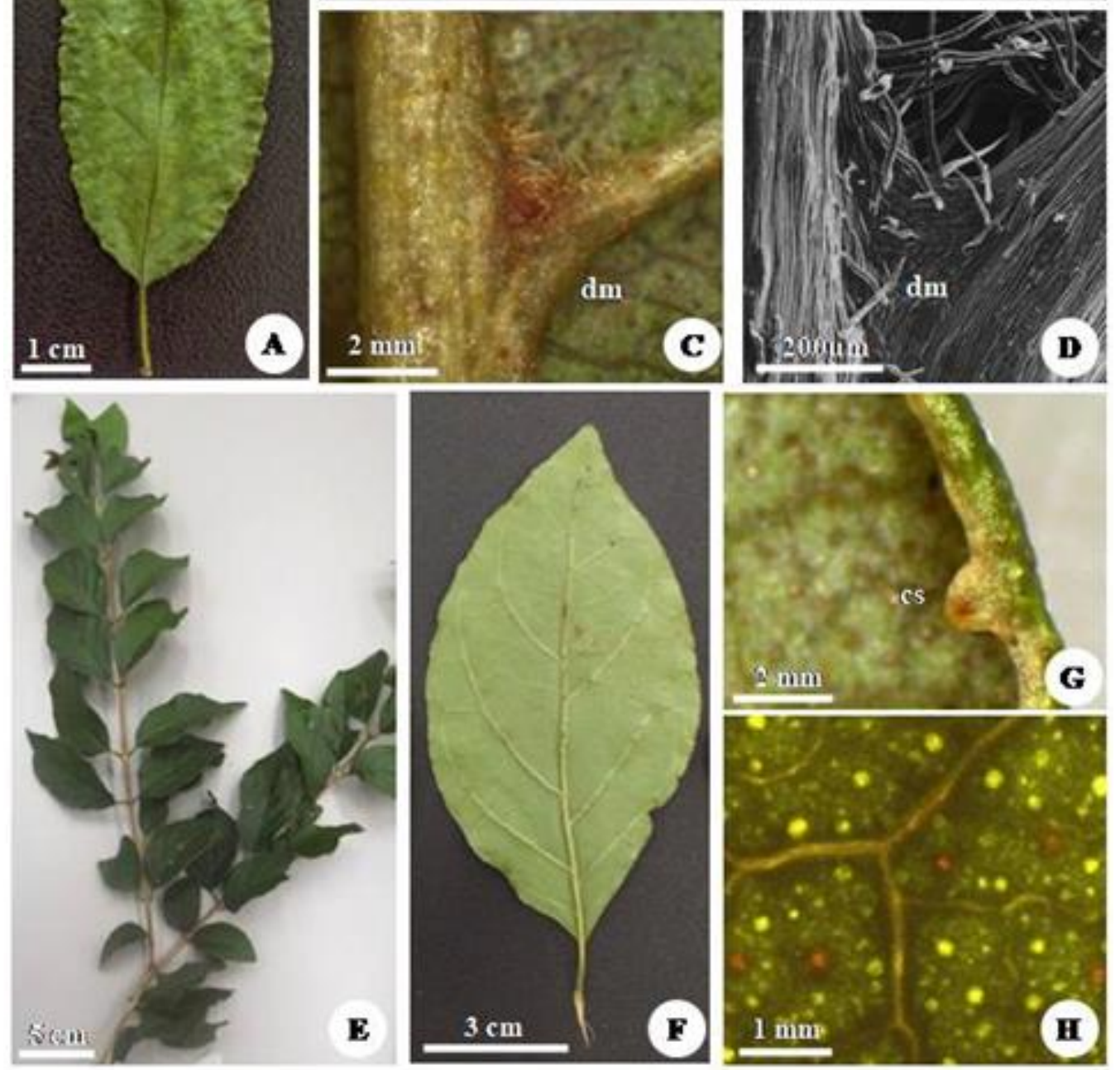

Figura 1 - Campomanesia xanthocarpa O. Berg (A-D): A - Lâmina foliar; B - Morfotipos de X1 a X7; C - Detalhe da domácia; D - Aspecto dos tricomas tectores. Campomanesia guaviroba (DC.) Kiaersk. (E-H): E - Ramos e filotaxia; F - Lâmina foliar; G - Bordo foliar, em detalhe cavidade secretora; $\mathrm{H}$ - Cavidades secretoras no limbo, em vista frontal superfície abaxial. (dm - domácia). 

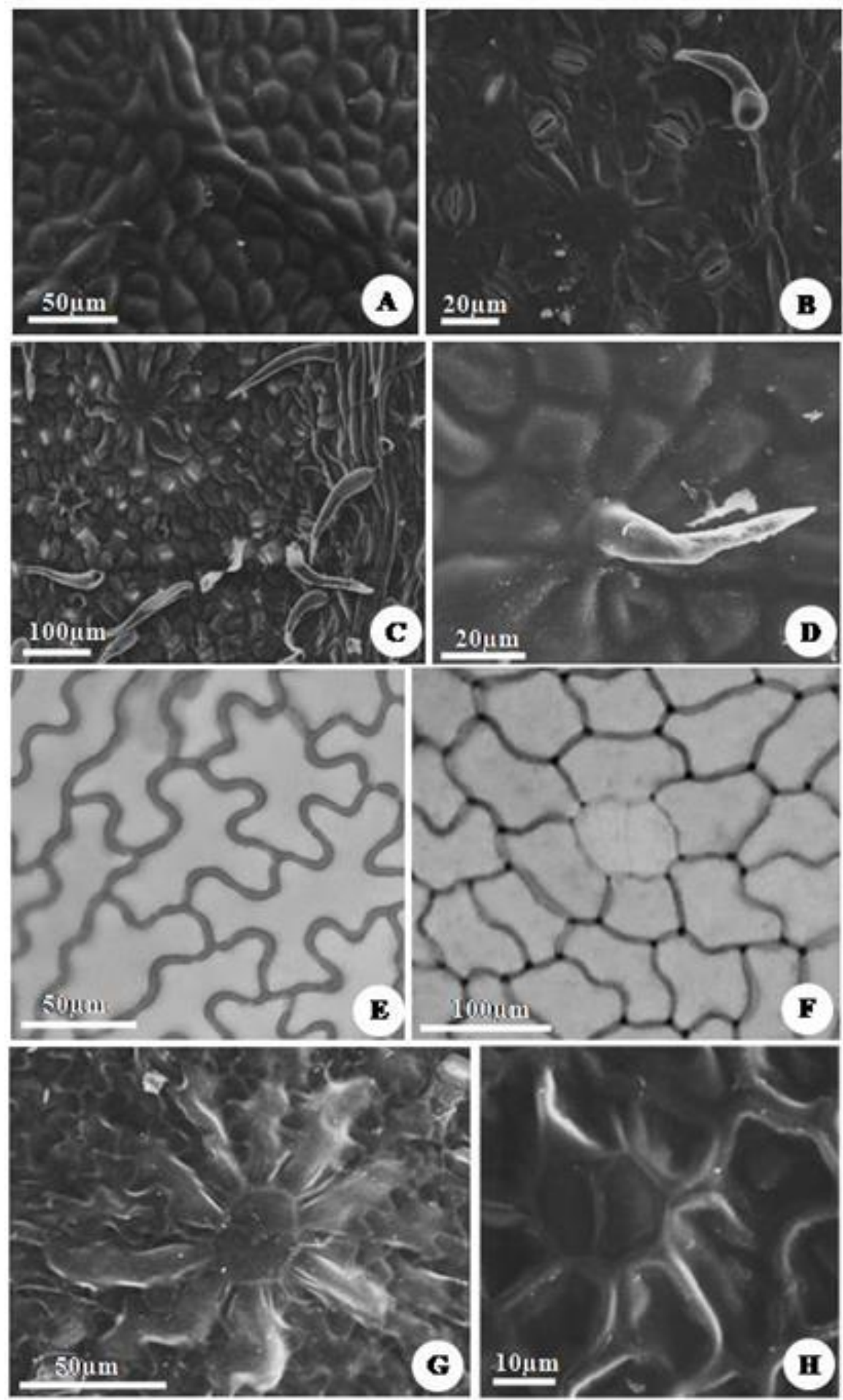

Figura 2: Campomanesia xanthocarpa O. Berg. Superfície da lâmina foliar (A-H); A - Face adaxial; B e C - face abaxial, em detalhe, tricomas tectores, estômatos e cavidades secretoras; D - tricoma tector na face adaxial, do morfotipo X7; E - Epiderme face abaxial; F - Epiderme adaxial; $\mathrm{G} \mathrm{e} \mathrm{H}$ - cavidade secretora. 

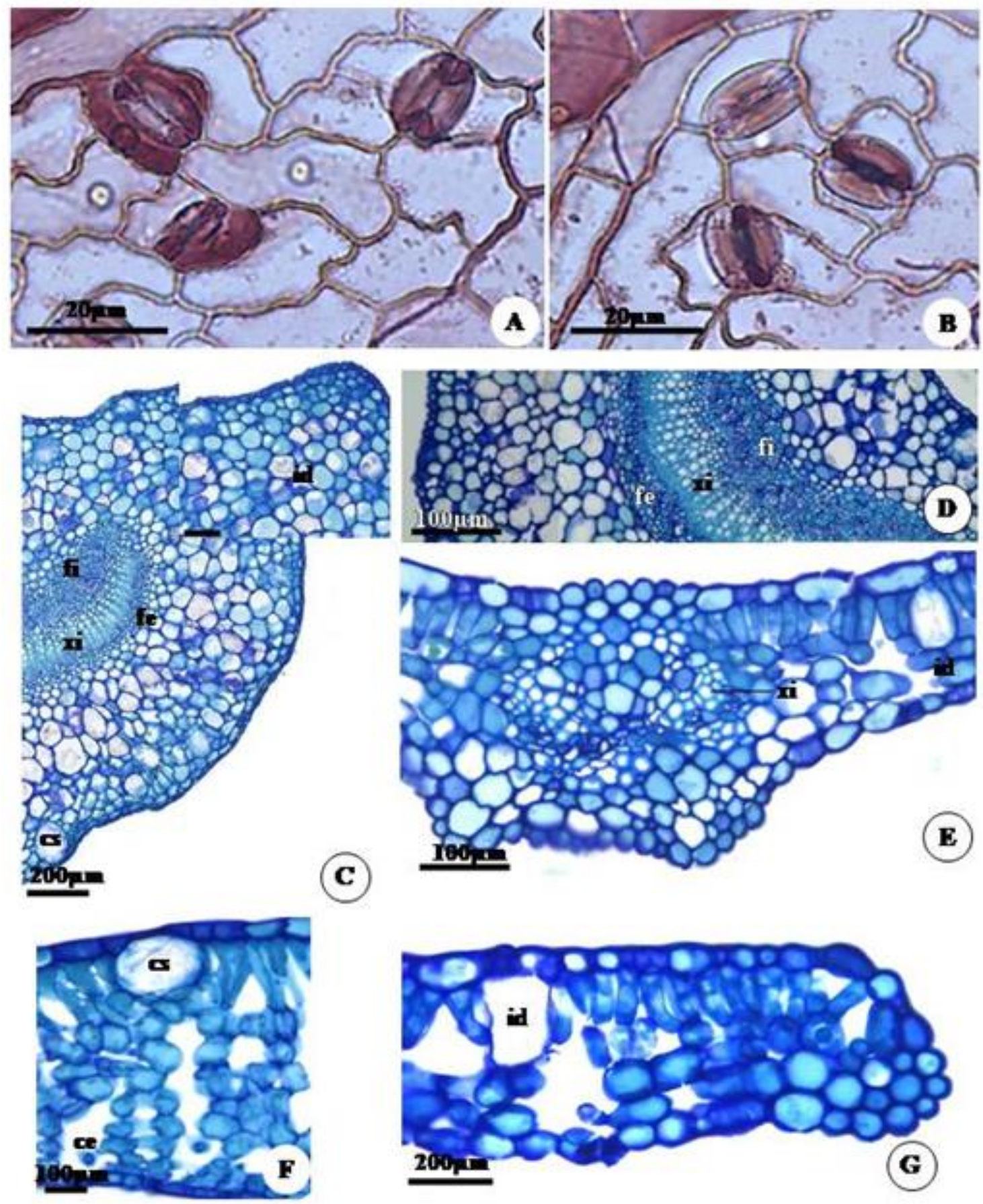

Figura 3: Campomanesia xanthocarpa O. Berg. Lamina foliar. A e B - Epiderme face abaxial, detalhe dos estômatos anomocíticos e paracíticos; C - Pecíolo em secção transversal, detalhe idioblasto cristalífero; D e E - Secção transversal da nervura central, na região mediana e no ápice, respectivamente; F e G - Secção transversal do limbo, na região do mesofilo e no bordo. (ce - câmara subestomática; cs cavidade secretora; fe - floema externo; fi - floema interno; id - idioblasto). 

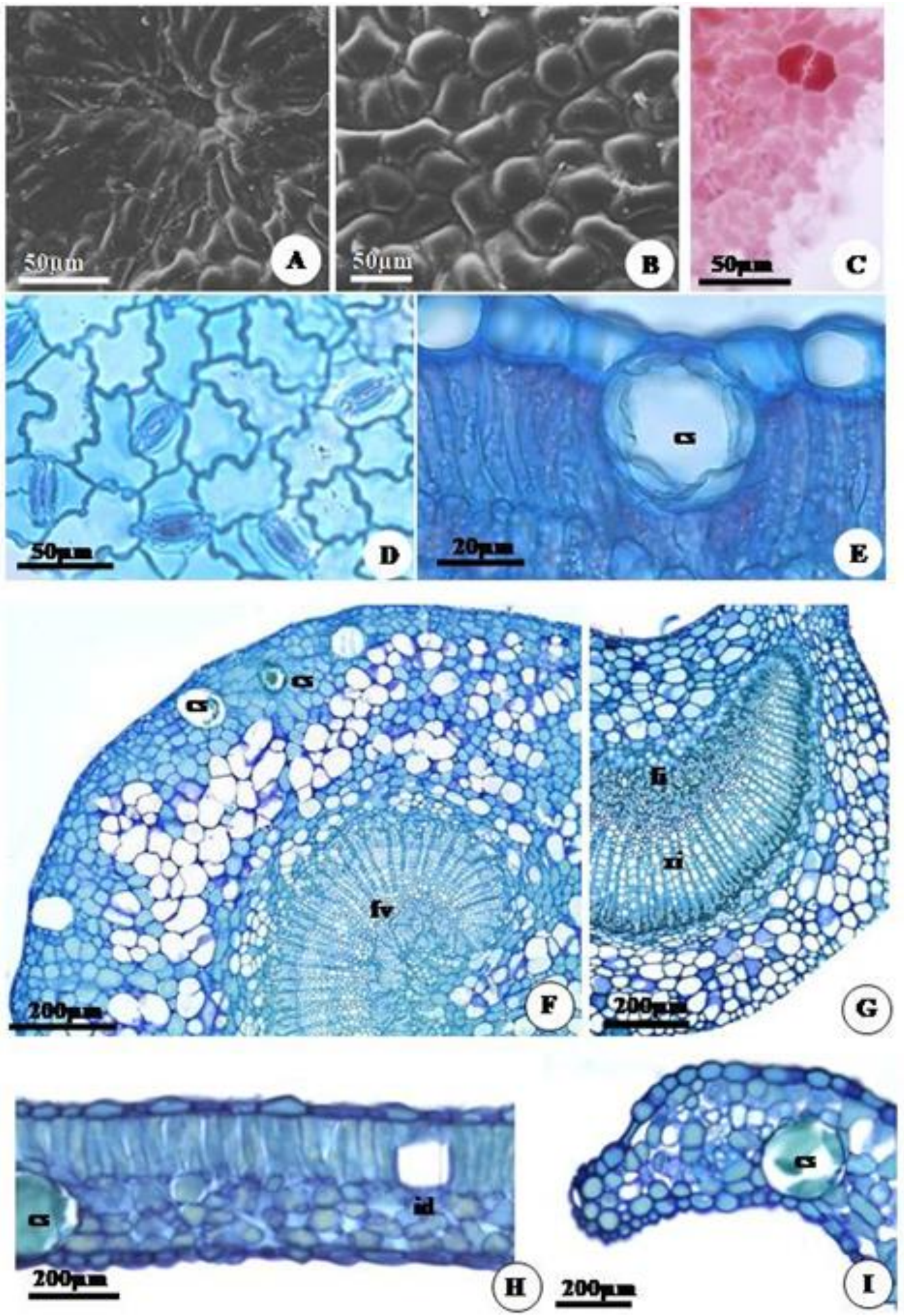

Figura 4: Campomanesia guaviroba (DC.) Kiaersk. Lamina foliar. A-D Epiderme em vista frontal; A e B cutícula lisa e detalhe da cavidade secretora; C e D - face abaxial, detalhe células teto e estômatos paracitcos e anomocíticos; E - Secção transversal do limbo, em detalhe a cavidades secretora. F - Secção transversal do pecíolo; $G$ - Secção transversal base da folha. (cs - cavdade secretora; fi - floema interno; fv- feixe vascular; id - idioblasto; xi - xilema) 


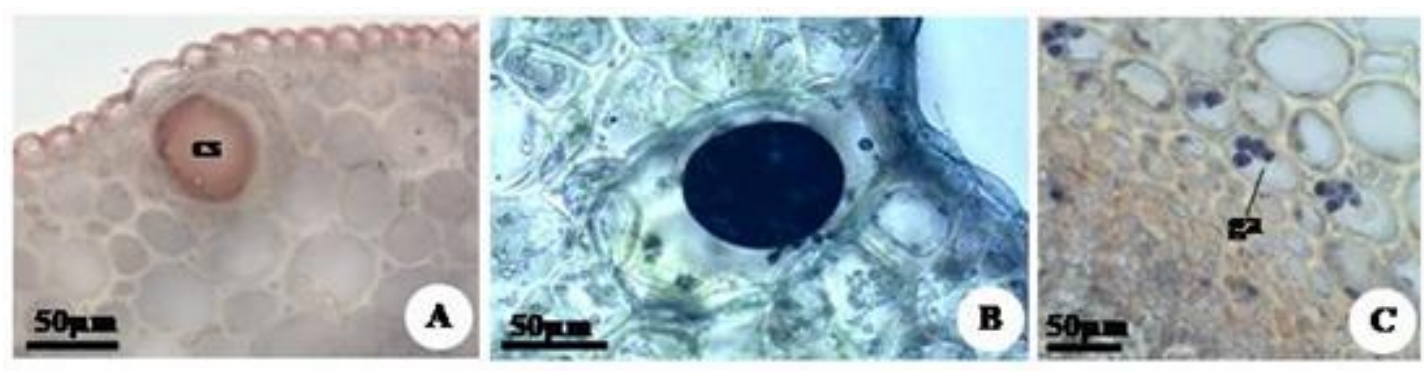

Figura 5: Campomanesia xanthocarpa O. Berg. A e B - Secção transversal do pecíolo. A e B - detalhe cavidade da cavidade secretora com conteúdo lipídico, corado com Sudan IV(vermelho) e com Sudan Black B (azul); C - Grãos de amido na endoderme do feixe vascular, evidenciados com Lugol. (cs- cavidade secretora; ga - grãos de amido). 